\title{
Reconnaissance Study on Saltwater Intrusion Control at Main Raw Water Pumping Station of Metropolitan Waterworks Authority (Thailand)
}

\author{
Lerdlekha Sriratana and Krisda Bisalyaputra
}

\begin{abstract}
At present, saltwater intrusion in water resource is highly concerned as it could severely affect various sectors such as water utilization, irrigation as well as water supply production process. This study aims to assess the problem of saltwater intrusion in raw water resource of Metropolitan Waterworks Authority (Thailand). In addition, a conceptual framework to handle this crisis was developed based on literature review and revised by the experts for applicability and sustainability of the proposed framework. From study, it can be noted that saltwater intrusion in this case could be effectively controlled by integrating several methods such as water diversion, fresh water discharge, barrage with sluice gates, submerged weir/rubber dam, Abstraction Desalination and Recharge (ADR), and Cutoff wall. Moreover, water resource management should be well considered and applied to overcome such problem.
\end{abstract}

Index Terms-Saltwater, intrusion, water supply, water resource.

\section{INTRODUCTION}

Climate change causes many environmental problems such as drought, flood, storm, storm surge, and saltwater intrusion. Saltwater intrusion has increasingly affected raw water resources, i.e. rivers, and water supply production process for years. Sustainable solutions for this crisis are vital in order to control the effects on irrigation and water utilization of residential and industrial sectors. Chaophraya River is the main raw water resource of Bangkok metropolitan provinces including Bangkok, Samut Prakarn, and Nonthaburi which are located in low land and close to Thai Gulf as shown in Fig. 1. Metropolitan Waterworks Authority (Thailand) or MWA is responsible for providing and distributing water supply in these areas by using raw water resource mainly from Chaophraya River with the total capacity of 5 million cubic meters per day. There are about 7 steps of MWA water production process which consists of Raw Water Quality Improvement, Chemical Feeding, Sedimentation, Filtration, Disinfection, Water Quality Control, and Transmission and Distribution System as illustrated in Fig. 2 [1]. However, MWA has been challenged by saltwater intrusion during the drought of each year especially at Samlae Raw Water Pumping Station, the main intake station, which is about 96 $\mathrm{km}$ away from Thai Gulf. As a result, lack of raw water for producing water supply and also poor quality of water supply

Manuscript received February 22, 2018; revised July 12, 2018

L. Sriratana and K. Bisalyaputra are with Ramkhamhaeng University, Bangkok, 10240, Thailand (e-mail: lerdlekha_s@ru.ac.th, Akemail.a@gmail.com). due to high level of salt contamination can be observed. This study aims to develop the short-term and long-term plans as a conceptual framework for MWA to overcome saltwater intrusion problem based on literature review from various case studies around the globe. In addition, this developed framework was then reviewed by the experts regarding to water resource management to ensure the applicability and sustainability of plans.

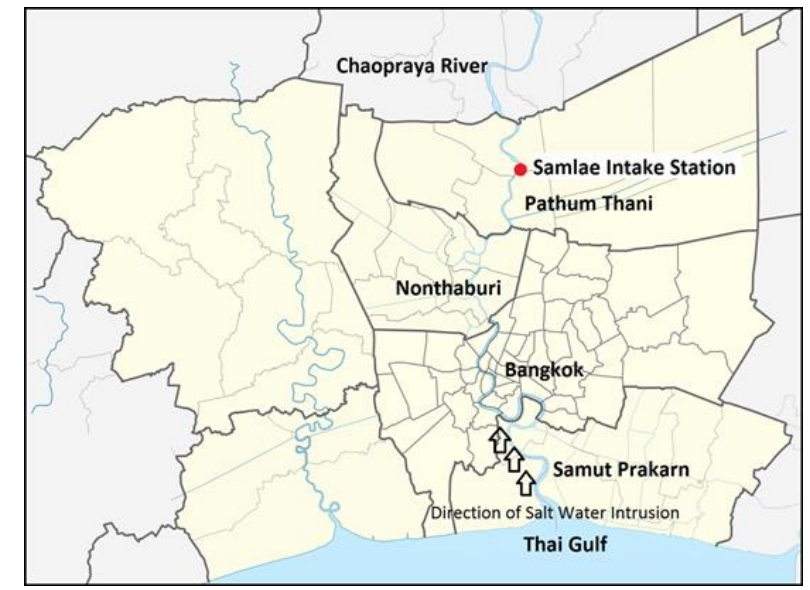

Fig. 1. Bangkok Metropolitan Map and Direction of Saltwater Intrusion. (Map Source: https://th.wikipedia.org/)

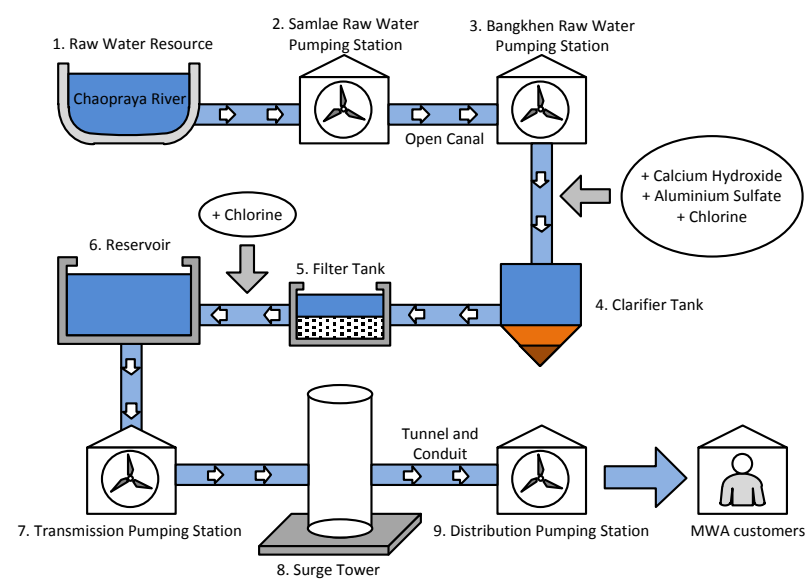

Fig. 2. MWA water production process [1].

\section{LITERATURE REVIEW}

There are about 15 methods which would be applicable for controlling intrusion of saltwater in various areas around the globe [2-19]. Details are summarized as follows:

1) Water diversion

Details/Benefits: Use of excessive fresh water via open 
canal or tunnel for pushing saltwater and for diversion purposes.

Locations: Areas with adequate fresh water and availability of diversion passages, river basins of Thailand, and north of China.

Limitations: Negative influences on estuary and not sustainable

\section{2) Water discharge}

Details/Benefits: Optimization of water discharge based on tidal current.

Locations: Areas with suitable flow rate of canals or rivers, central region of India, south Florida (US).

Limitations: Considerable requirement of water and limited operation during the drought.

\section{3) Barrage with sluice gates}

Details/Benefits: Open or close sluice gates to control saltwater.

Locations: Small to medium-sized rivers, Pearl River (China).

Limitations: Effects on environment and high cost.

\section{4) Weir}

Details/Benefits: Saltwater control by using weir construction

Locations: Areas with limitation of water resource, $\mathrm{Wu}$ River (China).

Limitations: High cost.

\section{5) Submerged weir/rubber dam}

Details/Benefits: Flexible structure and sediment shield.

Locations: Small to medium-sized rivers.

Limitations: Need of lifetime maintenance for rubber dam.

6) Underground dam

Details/Benefits: Dam with underground construction for reserving water.

Locations: Areas with limitation of water resources.

Limitations: High cost and need of intensive surveys.

\section{7) Subsurface barriers}

Details/Benefits: Simple construction for controlling saltwater intrusion.

Locations: Japan.

Limitations: High cost and applicable only in specific locations.

\section{8) Cutoff wall}

Details/Benefits: Mitigating groundwater or saltwater flow, reserving groundwater, high efficiency and sustainability, and low impact on environment.

Locations: East coast of China.

Limitations: High cost, long-time construction, and need of intensive surveys.

\section{9) Reduction of groundwater pumping}

Details/Benefits: Mitigating intrusion rate of saltwater, and sustainable benefit from groundwater.

Locations: Coastal areas, and drought areas.

Limitations: Difficulty in water pumping control.

10) Saltwater pumping

Details/Benefits: Saltwater dissemination control by eliminating salt sediment.
Locations: Coastal areas, and drought areas.

Limitations: Need of intensive surveys for exploring pumping area (high concentration of salt sediment).

\section{1) Desalination}

Details/Benefits: Removal of salts and minerals from saltwater.

Locations: Areas with limitation of fresh water resources.

Limitations: Effects on environment, needs of special operation and management, and high cost.

12) Groundwater recharge

Details/Benefits: Man-made recharge for increasing groundwater level, and saltwater balance and control.

Locations: Coastal areas.

Limitations: Need of intensive surveys to explore recharging area.

13) Abstraction, desalination, and recharge ( $A D R)$

Details/Benefits: Abstraction of saltwater and recharge after desalination.

Locations: Areas with limitation of fresh water resources, and Middle East countries, i.e. Kuwait, Oman, Iraq.

Limitations: High cost.

\section{4) Natural materials (silty clays)}

Details/Benefits: Use of silty clays for creating a natural seal to prevent the intrusion of saltwater, and low cost.

Locations: Areas with availability of clays.

Limitations: Not sustainable.

\section{5) Alternating water resources}

Details/Benefits: Optimization of water resources.

Locations: Areas with plenty of water resources.

Limitations: Not applicable in drought areas.

\section{SAltWATER INTRUSiOn AT SAMLAE RAW WATER PUMPING STATION}

\section{A. Salinity of Raw Water}

Saltwater intrusion in the drought could significantly affect the quality of raw water at Samlae Raw Water Pumping Station. Consequently, the quality of MWA water supply could be influenced by excessive salinity of raw water. Salinity data during January to March 2017 are as illustrated in Fig. 3. The highest level of salinity was observed in March by 0.6 gram/liter which was about 3 times over the standard.

\section{B. MWA Initial Solutions}

Water supply production of MWA is the conventional water treatment process which could not eliminate salinity or chloride of raw water. Therefore, MWA has controlled the quality of raw water for water supply production based on salinity of water intake which should not exceed 0.25 gram/liter. At present, there are no specific or sustainable plans for preventing excessive salinity due to saltwater intrusion at Samlae Station. Initially, there are three reactive steps to perform when excessive salinity is observed as follows:

1) Occasionally pumping/operating to avoid the salinity over the standard.

2) Cooperating with Royal Irrigation Department to 
discharge water from Chaopraya Dam.

3) Cooperating with Royal Irrigation Department to diverse water from Mae Klong River and west canals.

However, the quality of water supply would not meet the standard by applying those solutions. MWA customers still complain about brackish water supply in the drought due to unsustainability of the initial solutions and limitations of water resources for discharge and diversion.

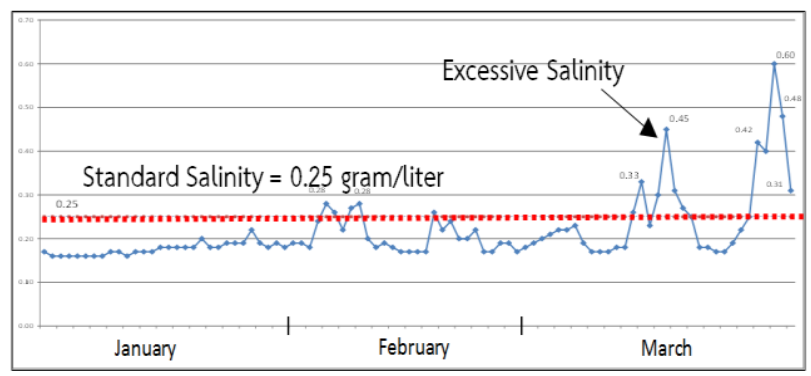

Fig. 3. Salinity variations during Jan - March 2017 at Samlae raw water pumping station [1].

\section{RECONNAISSANCE STUDY}

According to the literature review, the sustainable plans to control saltwater intrusion were developed by integrating several methods as well as applying in the appropriate phases with consideration of physical geography. For Chaopraya River basin, the preliminary plan as a conceptual framework to control saltwater intrusion at Samlae Intake Station based on literature review is as presented in Fig. 4 and Table I.

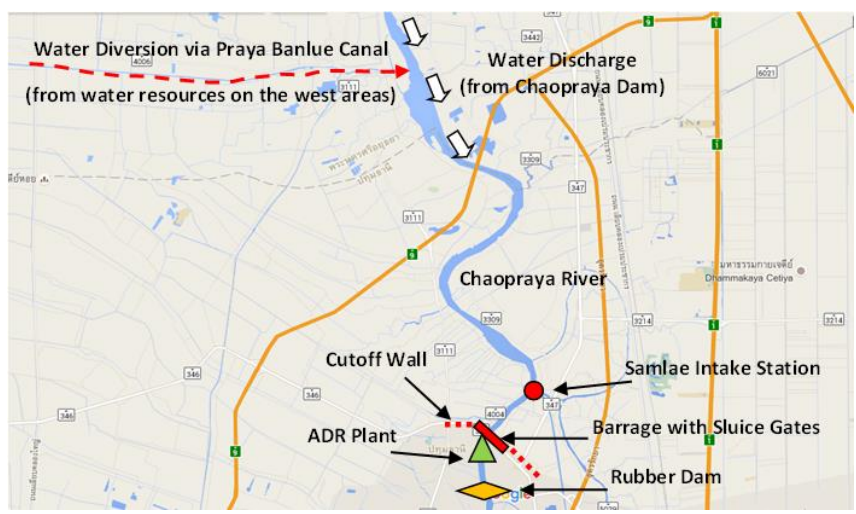

Fig. 4. Conceptual framework to control saltwater intrusion at samlae intake station.

(Map Source: https://maps.google.com/)

In this study, there are 8 suitable methods for adopting based on literature review expecting 12 years to complete the plan. All processes of the plan proposed are based on feasibility studies of saltwater intrusion control projects of MWA [19]. Details of the methods applied are as follows:

1) Water diversion: West water resources have high quality as well as excessive quantity which can be used for water diversion. Water diversion can be started from Mae Klong River via diversion canals namely Chorakae Sam Pan Canal, Song Phi Nong Canal and Praya Banlue Canal. Water could be finally arrived at Chaopraya River before reaching the intake station as shown in Fig. 5. There is also a MWA water pumping station at
Singhanad Gate Valve of Praya Banlue Canal that can be used to enhance the efficiency of diversion. This method could be adopted during the drought and barrage construction. However, it would be recommended to carry out about 6.5 years starting from the first year of the project due to unsustainability of the method.

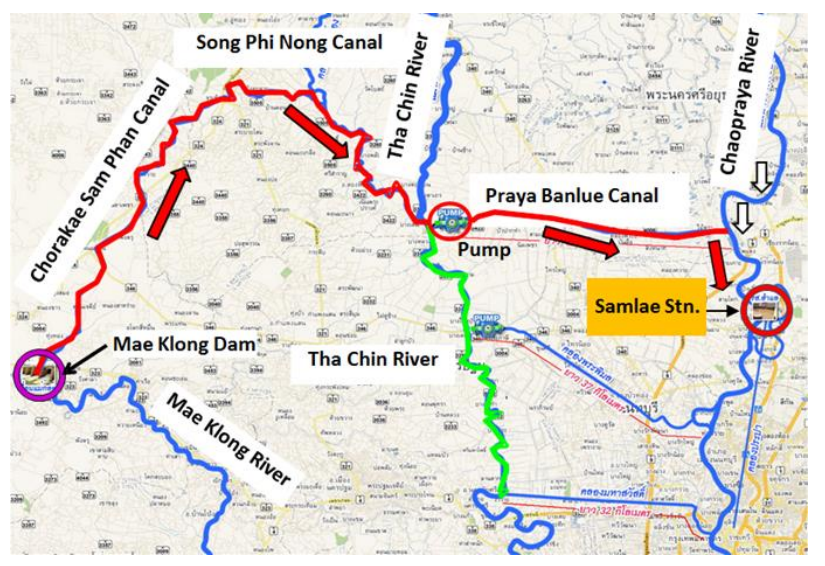

Fig. 5. Water diversion plan. (Map Source: MWA).

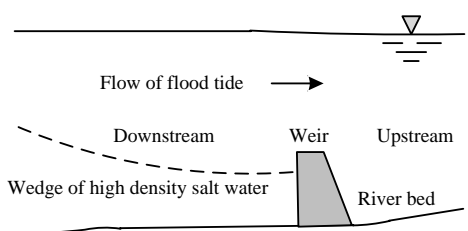

(a) Submerge weir
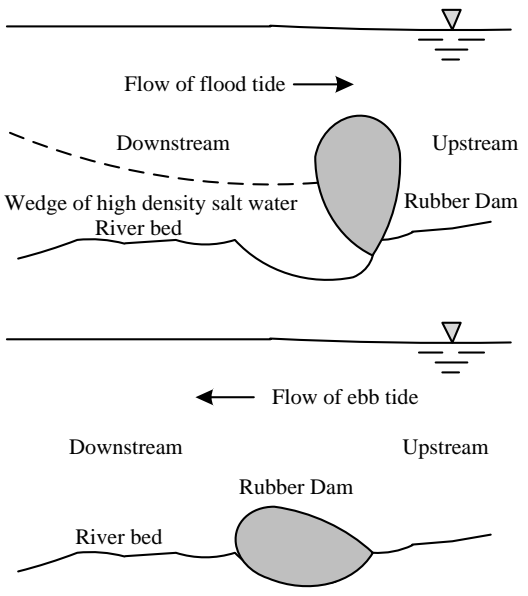

(b) Rubber Dam

Fig. 6. Submerged weir and rubber dam.

2) Water Discharge: Water discharge could be annually performed during construction of barrage which is about 8.5 years starting from the first year of the project. Although this method has been applied for years as an initial solution to control intrusion of saltwater, it would not be sustainable. During the drought, MWA should cooperate with Royal Irrigation Department to discharge water from Chaopraya Dam located at Chainat Province when the salinity exceeding 0.25 gram/liter and the flow rate of Chaopraya River at Pranakorn Sri Ayutthaya Province is lower than $100 \mathrm{~m}^{3} / \mathrm{sec}$. 
TABLE I: GANTT CHART OF SALTWATER INTRUSION CONTROL PROJECT AT SAMLAE INTAKE STATION

\begin{tabular}{|c|c|c|c|c|c|c|c|c|c|c|c|c|c|}
\hline No. & Method & $\begin{array}{c}\text { Year } \\
1 \\
\end{array}$ & $\begin{array}{c}\text { Year } \\
2\end{array}$ & $\begin{array}{c}\text { Year } \\
3\end{array}$ & $\begin{array}{c}\text { Year } \\
4\end{array}$ & $\begin{array}{c}\text { Year } \\
5\end{array}$ & $\begin{array}{c}\text { Year } \\
6 \\
\end{array}$ & $\begin{array}{c}\text { Year } \\
7 \\
\end{array}$ & $\begin{array}{c}\text { Year } \\
8 \\
\end{array}$ & $\begin{array}{c}\text { Year } \\
9\end{array}$ & $\begin{array}{c}\text { Year } \\
10 \\
\end{array}$ & $\begin{array}{c}\text { Year } \\
11 \\
\end{array}$ & $\begin{array}{c}\text { Year } \\
12 \\
\end{array}$ \\
\hline 1 & Water Diversion & \multicolumn{6}{|c|}{ Operation } & & & & & & \\
\hline 2 & Water Discharge & \multicolumn{8}{|c|}{ Operation } & & & & \\
\hline 3 & $\begin{array}{l}\text { Submerged Weir/ } \\
\text { Rubber Dam }\end{array}$ & \multicolumn{6}{|c|}{ Survey and Procurement Process } & \multicolumn{4}{|c|}{ Construction Period } & & \\
\hline 4 & Barrage with sluice gates & \multicolumn{5}{|c|}{ Survey and Procurement Process } & \multicolumn{5}{|c|}{ Construction Period } & $\begin{array}{r}\text { Preli } \\
\text { Ope }\end{array}$ & $\begin{array}{l}\text { nary } \\
\text { tion }\end{array}$ \\
\hline 5 & ADR & & \multicolumn{3}{|c|}{$\begin{array}{c}\text { Survey and } \\
\text { Procurement Process }\end{array}$} & & \multicolumn{4}{|c|}{ Construction Period } & \multicolumn{3}{|c|}{ Preliminary Operation } \\
\hline 6 & Cutoff Wall & & & \multicolumn{3}{|c|}{$\begin{array}{l}\text { Survey and Procurement } \\
\text { Processes }\end{array}$} & \multicolumn{4}{|c|}{ Construction Period } & & & \\
\hline 7 & $\begin{array}{l}\text { Renewable Water Resource } \\
\text { Management }\end{array}$ & \multicolumn{7}{|c|}{\begin{tabular}{c|c} 
& $\begin{array}{c}\text { Land Reclamation and System } \\
\text { Installation }\end{array}$ \\
\end{tabular}} & \multicolumn{3}{|c|}{ Preliminary Operation } & & \\
\hline 8 & New Intake Station & & & & & & & & & \multicolumn{4}{|c|}{ Survey and System Installation } \\
\hline
\end{tabular}

3) Submerged Weir/Rubber Dam: This method could operate depending on the tide as shown in Fig. 6. Submerged weir or Rubber dam should be constructed under water and could be upheaved to prevent saltwater intrusion during flood tide. The construction period would be about 9 years starting from the first year of the project. The location for construction should be well considered to avoid obstruction. Also, the depth of river should be appropriate and available for water transportation during ebb tide. The benefits of submerged weir and rubber dam are low requirement of maintenance compared to the life cycle, efficient and suitable for medium-wide rivers e.g. Chaopraya River, and less costs of construction compared to other methods.

4) Barrage with sluice gates: This method can be used for controlling saltwater intrusion effectively in many locations such as The Marina Barrage in Singapore which is ideal for isolating fresh water and sea water at Marina Bay and reserving raw water for water supply production process and The Barrage Projects in Netherland which are ideal for preventing sea water intrusion, coastal flood, and storm surge. The additional benefits of barrage with sluice gates are as follows:

4.1 In case of excessive water inside the barrage, the sluice gates should be opened to drain the excess amount of water into the lower area. On the other hand, the gates should be closed when the water level inside the barrage is lower than that outside the barrage.

4.2 During the drought, water diversion from west water resources through the barrage could be performed in order to control water level and to prevent the collapse of river bank. Moreover, the barrage can be essentially used to deplete water as well as reserve the excessive water during the flood.

4.3 If the water level inside the barrage and that at the lowest reaches are equal during flood tide, the sluice gates should be closed to prevent saltwater getting into the barrage. However, if water level inside the barrage is over the limitation, the exceeding water should be pumped out and delivered to the lower reaches.
4.4 Water resource management can be accomplished by use of the barrage. Also, the areas around barrage can be developed for benefiting communities nearby such as agriculture and ecotourism.

Although use of barrage could be the sustainable solution for controlling saltwater intrusion, long-time construction could be noticed. For Chaopraya River, it would take about 11 years of construction based on feasibility study of saltwater intrusion project.

5) Abstraction, Desalination, and Recharge (ADR): ADR is an essential method to extract salts and minerals from saltwater by using Reverse Osmosis (RO) in desalination process before recharging fresh water to the river and using in water supply production process. Although RO is a significant process in ADR plant, it may require large areas for construction that leads to high costs of construction and also operation. From preliminary study, ADR plant would take about 10.5 years for construction and installation of the processes starting from the middle of second year of the project.

6) Cutoff Wall: From literature review, Cutoff wall is one of the most effective and sustainable methods to control saltwater intrusion into water resources as well as to prevent and reserve underground water resources from saltwater contamination when integrating with other methods. However, this method would be high-priced due to requirement of sophisticated construction techniques. Moreover, work plan and location should be well considered due to long-time construction. From feasibility study, it would take about 7 years of construction starting from the third year of the project.

7) Renewable Water Resources Management: This method aims to optimize water resources by reserving rain and excess amount of water in large canals and detention basin near Chaopraya River based on the Royal Project namely Kaem-Ling of the King Bhumibol Adulyadej of Thailand. Kaem-Ling or literally Monkey's Cheek is the project to control flood around Bangkok areas. The east bank of Chaopraya River would be appropriate for this method due to availability of detention basin and canals. Drainage sluice gates should be installed and the canals should be connected together to effectively control water level. During the drought, the water reserved in the basin and 
canals can be used for consumption, irrigation and water diversion as needed. This method would take about 10.5 years to complete the plan starting from the first year of the project.

8) Replacement of Intake Station: This method would be the last option if previous mentioned methods could not be accomplished on time as the effects of saltwater intrusion could be noticeably observed year by year. Replacement of the main intake station would be the appropriate solution to prevent the effects on water supply production process. The new intake station should be located farther from Thai Gulf compared to Samlae Intake station in order to minimize effects of saltwater intrusion on water supply production process while still benefiting water resource from Chaopraya River. However, the location of new intake station should be well considered as the additional costs of water distribution system and reservoirs should be required for MWA production process.

\section{DISCUSSION}

From preliminary plan, about ten experts on water resource management from MWA and institutions were interviewed to review and discuss about the feasibility of the conceptual framework. It can be noted that the proposed plan would be applicable with well consideration of budget, time period, and agreement from communities which could be affected by project constructions. Also, Environmental Impact Assessment (EIA) should be carried out before starting the project. Moreover, the project areas could be developed for tourism purposes which would be the passive contribution of the project to the communities nearby. Furthermore, MWA should provide more cooperative actions on water resource management of Chaopraya River with other organizations such as Ministry of Agriculture and Cooperatives, Department of Highways, Subdistrict Administration Organization, and other related governmental and private organizations.

\section{CONCLUSION}

In conclusion, saltwater intrusion has been severely and increasingly observed for many years. The major causes of this problem would be influenced by drought, storm search, and increase of water resource requirement from several sectors. Metropolitan Waterworks Authority (Thailand) or MWA is responsible to provide water supply in Bangkok metropolitan provinces by using raw water resource mainly from Chaophraya River in water supply production process. However, saltwater intrusion problem affects the quality of raw water resource especially at Samlae Water Pumping Station which is the main intake station of MWA. There are several methods that would be effective to control saltwater intrusion based on literature review including water diversion, water discharge, submerged weir/rubber dam, barrage with sluice gates, Abstraction, Desalination, and Recharge (ADR), cutoff Wall, and renewable water resources management which should be integrated in the project plan. This preliminary plan was then reviewed and discussed by the experts. It can be concluded that the proposed plan would be feasible for application. However, the project should be well studied especially on budget, time period, public hearing, and environmental impact. If previous mentioned methods could not be accomplished on time, replacement of the main intake station should be considered. The new main intake station should be located farther from Thai Gulf compared to Samlae Intake station to minimize the effects of saltwater intrusion.

\section{ACKNOWLEDGMENT}

Authors wish to thank Mr. J. Thanaboon and MWA for valuable information to complete this study.

\section{REFERENCES}

[1] Metropolitan Waterworks Authority, Bangkhen Water Treatment Plant, MWA, Bangkok, 2013.

[2] L. Shi, and J. J. Jiao, "Seawater intrusion and coastal aquifer management in China: A review," Environmental Earth Sciences, vol. 72, pp. 2811-2819, March 2014.

[3] K. A. Rahi and T. Halihan, "Changes in the salinity of the Euphrates river system in Iraq," Regional Environmental Change, vol. 10, pp. 27-35, March 2010.

[4] Y. T. Kim, "Effect of freshwater on the long-term salt balance in the northern and central Indian river lagoon," Ph.D. dissertation, Florida Tech, Florida, 2001.

[5] D. C. M. Augustijn, M. V. D. Berg, E. De Bruine, and H. Korving, "Dynamic control of salt intrusion in the mark-vliet river system, the Netherlands," Water Resources Management, vol. 25, pp. 1005-1020, February 2011.

[6] W. B. Chen, W. C. Liu, and L. T. Huang, "The influences of weir construction on saltwater intrusion and water quality in a tidal estuary - Assessment with modeling study," Environmental Monitoring and Assessment, vol. 185, pp. 8169-8184, October 2013.

[7] J. Cai, T. Taute, and M. Schneider, "Recommendations of controlling saltwater intrusion in an inland aquifer for drinking-water supply at a certain waterworks site in Berlin (Germany)," Water Resources Management, vol. 29, pp. 2221-2232, May 2015.

[8] S. S. Marrufo, "An integrated geological and geophysical study of the fresh and brackish water boundary in the Hueco Bolson,West Texas," M.S. thesis, Univ. of Texas at El Paso, Texas, 2011.

[9] P. Yuansheng and T. Zhaohui, "Integrated project management of sustainable water storage and seawater intrusion prevention in a Costal City," in Proc. $2^{\text {nd }}$ IEEE International Conference on Computer Science and Information Technology, pp. 263-267, Beijing, 2009.

[10] E. H. Alali, "Implementing a treated wastewater recharge technique and reverse osmosis unit system for water sustainability," Ph.D. dissertation, Colorado State Univ. Fort Collins, Colorado, 2004.

[11] P. M. Barlow, and E. G. Reichard, "Saltwater intrusion in coastal regions of north America," Hydrogeology Journal, vol. 18, pp. 247-260, February 2010.

[12] A. R. Kacimov, M. M. Sherif, J. S. Perret, and A. Al- Mushikhi, "Control of sea-water intrusion by salt-water pumping: Coast of Oman," Hydrogeology Journal, vol. 17, pp. 541-558, May 2009.

[13] N. Nawa and K. Miyazaki, "The analysis of saltwater intrusion through Komesu Underground Dam and water quality management for salinity," Paddy and Water Environment, vol. 7, pp. 71-82, June 2009.

[14] J. Wu, F. Meng, X. Wang, and D. Wang, "The development and control of the seawater intrusion in the eastern coastal of Laizhou Bay, China," Environmental Geology, vol. 54, pp. 1763-1770, June 2008.

[15] G. Zhenren and Y. Lirong, "Comparison of engineering options for seawater intrusion control at river mouths," in Proc. $5^{\text {th }}$ Brunei International Conference on Engineering and Technology, pp. 1-5, Bandar Seri Begawan, 2014.

[16] H. Chen, Y. Zhang, X. Wang, Z. Ren, and L. Li, "Salt-water intrusion in the lower reaches of the Weihe River, Shandong Province, China," Hydrogeology Journal, vol. 5, pp. 82-88, March 1997.

[17] X. Kun, Z. Jianrong, and G. Yuliang, "Impact of the eastern water diversion from the south to the north project on the saltwater intrusion 
in the Changjiang Estuary in China," Acta Oceanologica Sinica, vol. 31, pp. 41-58, May 2012.

[18] J. J. Houle, "Community decisions about innovations in water resource management and protection," Ph.D. Dissertation, Univ. of New Hampshire, New Hampshire, 2015.

[19] J. Thanaboon, "The study of the prevention of saltwater contamination in Metropolitan Waterworks Authority,” M.Eng. thesis, Engineering Law and Inspection, Ramkhamhaeng Univ., Bangkok, Thailand, 2016.

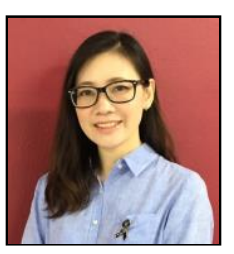

Lerdlekha Sriratana was born in Chiang Rai, Thailand on October 3, 1977. She received the B.Eng. and the M.Eng. in electrical engineering from King Mongkut's Institute of Technology Ladkrabang, Thailand in 1999 and 2001, respectively, the M.Eng. in engineering MANAGEMENT from Queensland University, Australia in 2004 and the D.Eng. in Energy technology from Asian Institute of Technology, Thailand in 2010 .

She has joined Department of Industrial Engineering, Faculty of Engineering at Ramkhamhaeng University, Bangkok, Thailand as a lecturer since 2001. She is now an Assistant Professor and Deputy Dean for Welfare of the faculty. Her research expertise is energy technology as well as industrial instruments and management.

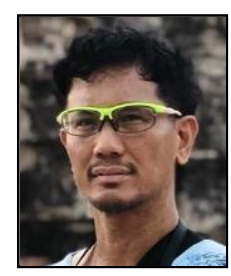

Krisda Bisalyaputra graduated with a bachelor degree in major of electrical engineering and minor in criminal justice from the University of Miami in Florida state, USA. He also received the master degree in industrial Engineering from the same institute. He continued to pursued the Ph.D in industrial engineering From Ubonrejathanee University, Thailand and his Bachelor of Law from Ramkhamaheng University. His went to legal specialize training in intellectual property law from ministry of commerce in Japan. He is the member of Thai Bar association and member of Thai Engineering council. With more than 20 years of experience, After joining Ramkhamaheng university. Dr. Krisda Bisalyaputra has worked on several valuable projects, including Business Incubation and startup funding. He launched his career at the university, where he was responsible for teaching, researching, and consulting. His expertise and commitment has allowed him to be recognized as an experienced academic. His service also included to the Thai Government as the consultant to the Minister of Labor and the served as Executive committee for national safety. At present, he is serving as the chairman of the graduate study in school of engineering. He plays a major role in developing, managing, and teaching. Through his commitment to this role, he has helped improve the quality, innovation, and superior standard education. 